\title{
A rare case of laparoscopy towards SLE with lupus mesenteric vasculitis induced ascites
}

\author{
Kamleshsingh Shadhu ${ }^{1,2+}$, Dadhija Ramlagun ${ }^{1,2+}$ and Xiaochun Ping ${ }^{1,2^{*}}$
}

\begin{abstract}
Background: Diagnosis and management of acute abdomen secondary to systematic lupus erythematosus (SLE) has always been a clinical challenge.

Case presentation: A 21-year-old lady, with BMI 17.7, presented to our department with acute abdomen. Laparoscopy was carried out to exclude surgical emergency when conservative regimen failed. The patient revealed a history of purpuric changes and lupus test was positive for SLE.

Conclusion: Based on our experience, early laparoscopy to alleviate acute abdomen has shown to improve the prognosis of the patient.
\end{abstract}

Keywords: Systematic lupus erythematosus (SLE), Laparoscopy, Acute abdomen

\section{Background}

Systematic lupus erythematosus (SLE) is a chronic inflammatory disease. The extent of gastrointestinal tract involvement in patients with SLE is rare and the outcomes remain unclear. A retrospective singlecenter analysis reports an incidence of $0.6 \%$ of gastrointestinal complications in patients with SLE [1]. The use of early surgical intervention instead of surgical therapy as an optimum treatment for lupus mesenteric vasculitis (LMV) is controversial [2-4]. We here in report a case of a young lady who had abdominal ascites via SLE with LMV.

\section{Case presentation}

A 21 years old female patient, of body mass $47 \mathrm{~kg}$ and BMI 17.7, came to our emergency department due to paroxysmal abdominal pain for 4 days. The pain was intermittent, moderate to severe, cramping in the

\footnotetext{
* Correspondence: pingxiaochun@jsph.org.cn

${ }^{\dagger}$ Kamleshsingh Shadhu and Dadhija Ramlagun contributed equally to this work.

'Department of General Surgery, The First Affiliated Hospital of Nanjing Medical University, Guangzhou Road, 300, Gulou District, Nanjing, Jiangsu 210029, People's Republic of China

${ }^{2}$ Department of Gastric Surgery, The First Affiliated Hospital of Nanjing Medical University, Guangzhou Road, 300, Gulou District, Nanjing, Jiangsu 210029, People's Republic of China
}

epigastric area. She also had diarrhoea 2 days ago and hadn't had any bowel movements ever since. A similar episode occurred 2 months ago which subsided spontaneously over few days. However, the pain she had this time was so severe that medical treatments she received in urgent clinic, at another hospital, couldn't provide relief. Upon arriving at the emergency room of our hospital, her vital signs were $37.2^{\circ} \mathrm{C}$, heart rate $98 \mathrm{bpm}$, respiratory rate $18 \mathrm{bpm}$, blood pressure 126/ $92 \mathrm{mmHg}$. Physical examination revealed a moderately distended abdomen, tenderness in the epigastric area without rebound, positive shifting dullness, and hypoactive bowel sounds. Laboratory tests found white blood cells count was $17.2^{*} 10^{\wedge} 9 / \mathrm{L}$, neutrophils $88.7 \%$ and D-dimer $11.7 \mathrm{mg} / \mathrm{L}$. Abdominal CT scan showed dilatation of proximal small intestine with thickened walls and air-fluid levels and accumulation of massive abdominal ascites. There was no sign of occlusion or filling defect in the superior mesenteric artery and vein, or their distal branches (Figs. 1 \& 2). She denies any past medical history or on any medications. She is

(c) The Author(s). 2019 Open Access This article is distributed under the terms of the Creative Commons Attribution 4.0 International License (http://creativecommons.org/licenses/by/4.0/), which permits unrestricted use, distribution, and reproduction in any medium, provided you give appropriate credit to the original author(s) and the source, provide a link to the Creative Commons license, and indicate if changes were made. The Creative Commons Public Domain Dedication waiver (http://creativecommons.org/publicdomain/zero/1.0/) applies to the data made available in this article, unless otherwise stated. 


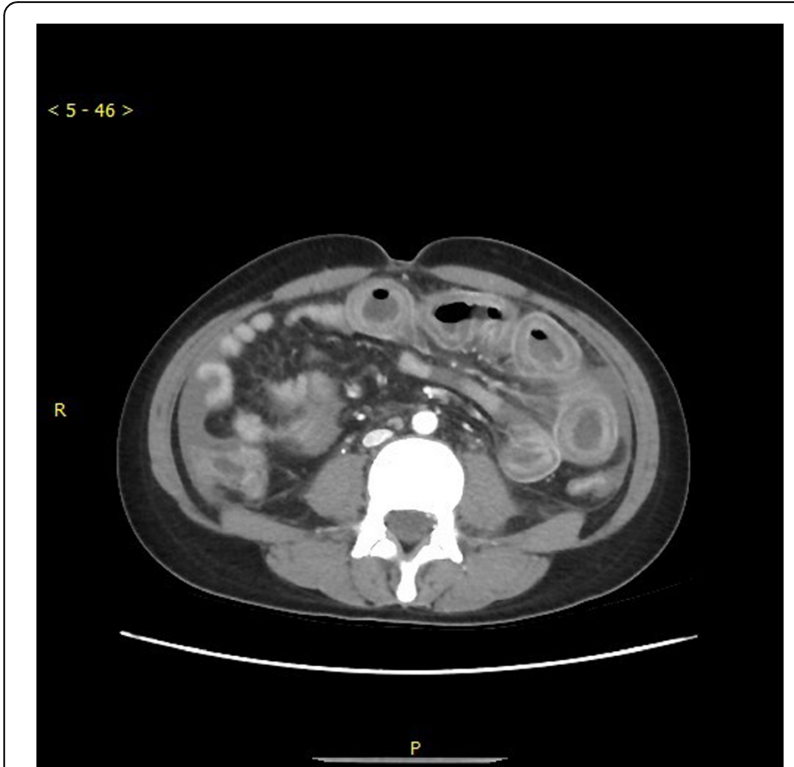

Fig. 1 Transverse section CT scan showing dilatation of small intestine and ascites

sexually active and had her immunization up to date. Due to the worsening nature of her pain after conservative treatments, acute abdomen was suspected, and a diagnostic laparoscopy was performed to exclude any surgical emergencies. During the surgery, $2500 \mathrm{~mL}$ of yellowish ascites were drained (Fig. 3). Multiple adhesive bands were seen between the liver and the diaphragm, and in the pelvic cavity (Figs. 4a \& 4b). Part

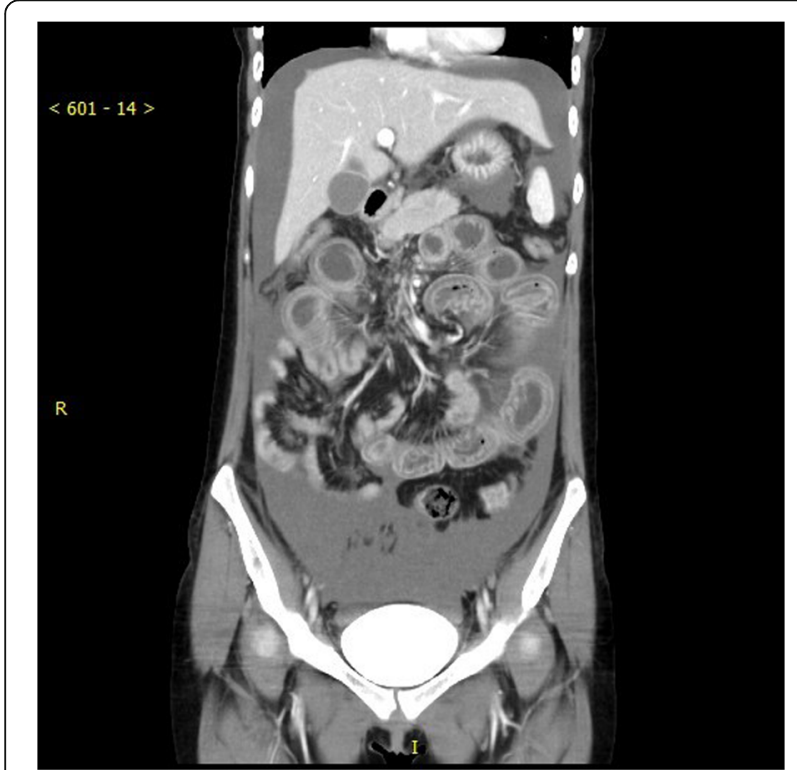

Fig. 2 Coronary section of $\mathrm{CT}$ scan showing dilatation of proximal small intestine, massive ascites, no occlusion or filling defects in major mesenteric vessels

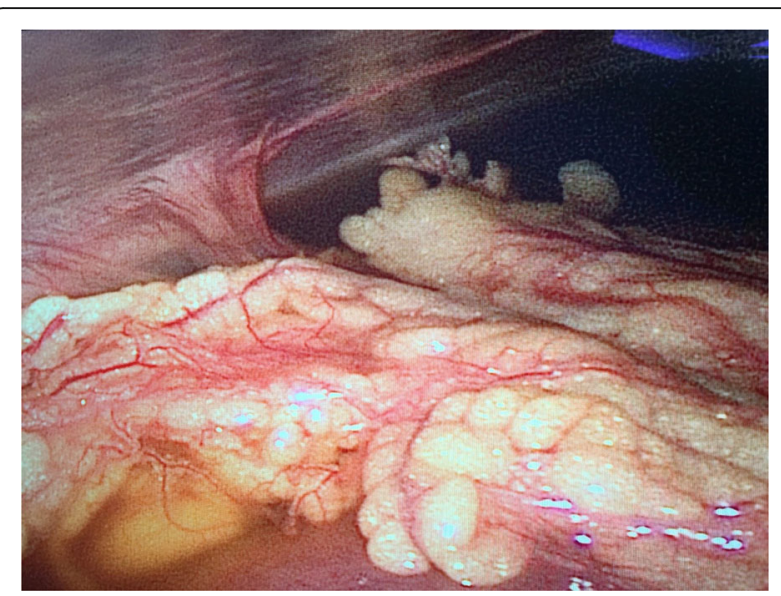

Fig. 3 Intraoperative picture showing massive yellowish ascites

of omentum was adhered to the right side of the pelvic floor, which was lysed. Inspection of the whole length of small intestine showed dilation and thickened walls of the jejunum, $50 \mathrm{~cm}$ in length (Fig. 5). The ileum was normal, and no obstruction point was found. The colour and peristalsis of the intestines were normal. The patient was diagnosed as idiopathic peritonitis and pseudo-ileus intra-operatively. The characteristics of the drained ascites was shown in Table 1. Supportive treatments as well as antibiotics, including cefoperazone and metronidazole, were given immediately after the surgery as Fitz-Hugh-Curtis syndrome was also suspected. However, on the morning of postoperative day (POD) 1, another $2950 \mathrm{~mL}$ of ascites were found in the drainage tube. The patient was haemodynamically unstable. Aggressive resuscitation was initiated. The family of the patient later revealed that 6 months ago she had multiple erythema on her palms and cheek, which were purpuric like changes and subsided after herbal medicine. The lupus mesenteric vasculitis (LMV) was then suspected. The lupus tests together with other diagnostic tests were carried out. Their results were shown in Tables 2 and 3. She was positive for anti-nuclear antibody (ANA), anti-Smith, anti-u1-snRNP, anti-Ro, anti-dsDNA antibodies and low in complements $\mathrm{C} 3$ and $\mathrm{C} 4$. The patient was diagnosed with systematic lupus erythematosus (SLE) with lupus mesenteric vasculitis. She was treated with $80 \mathrm{mg}$ IV methylprednisolone per day and $0.2 \mathrm{~g}$ of oral hydroxychloroquine twice a day with rapid improvement of abdominal symptoms. She resumed normal diet few days after her ascites diminished and was discharged on POD 12. On follow-up, the patient continued her treatments at the rheumatology department and had no surgical associated complications. 

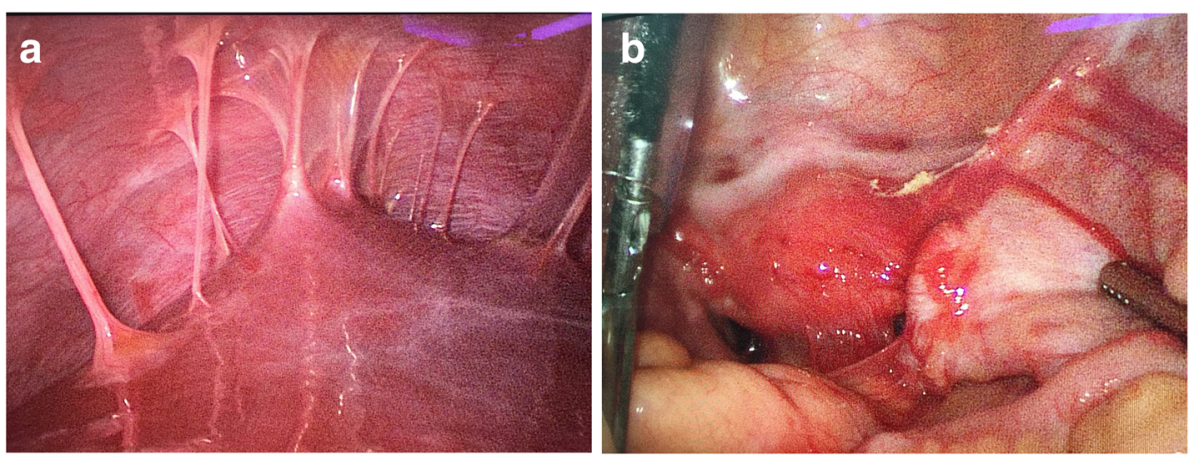

Fig. 4 a Intraoperative picture showing adhesive bands (violin-string) between the liver and the diaphragm. $\mathbf{b}$ Intraoperative picture showing adhesions in the pelvic cavity

\section{Discussion and conclusion}

It is observed that in $87 \%$ of patients with SLE, involving gastrointestinal tract, abdominal pain was almost a constant sign [5]. Besides, it has been shown, by Medina et al. [6], that adults with SLE, who had intrabdominal vasculitis or thrombosis, had higher systematic lupus erythematosus disease activity index (SLEDAI) scores and were associated with surgical abdomen. Since 1993 the SLEDAI has been used as an index of disease activity and the score for our case was 8 [7]. This was calculated via the features of proteinuria (4), malar rash (2) and hypocomplementemia (2) which were present in the lady [7]. In a study the aetiologies of abdominal pain have been compared in patients with active and inactive SLE in which patients with active disease (SLEDAI score $>5$ ) have a higher prevalence of LMV than those with inactive disease. Therefore, this showed that mesenteric vasculitis can be combined with thrombocytopenia, central nervous system involvement, cutaneous vasculitis and lymphopenia [6].

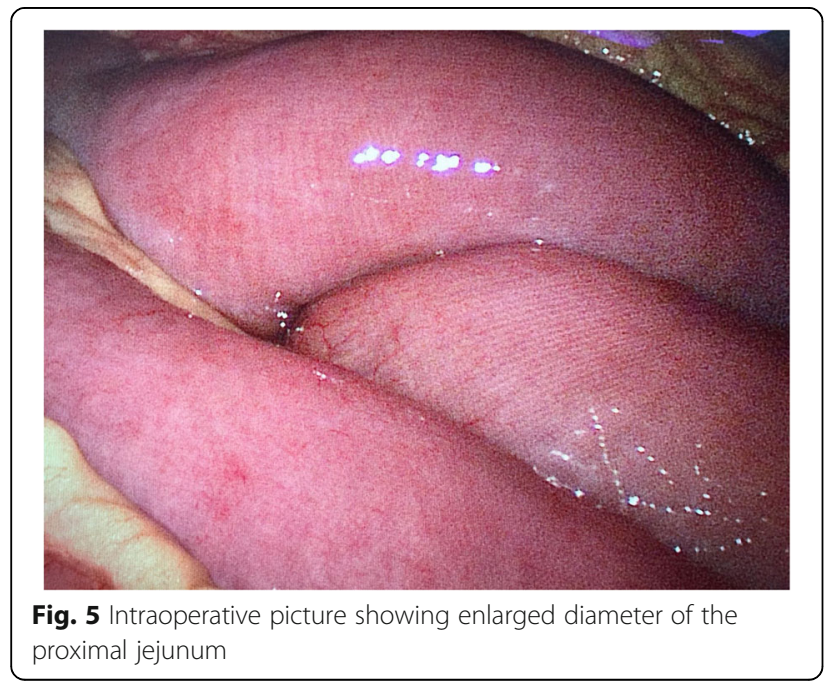

Besides, a case series reported by Kishimoto et al. [8] showed that patients with acute gastrointestinal distress syndrome have recurrent lupus enteritis based on mesenteric vasculopathy characterised by reversible intestinal wall oedema accompanied by significant hypocomplementemia. Another study showed that anti-proliferative cell nuclear antigen antibody was found to be more frequently detected than in lupus patients without pseudo-ileus [9]. SLE-reported pseudo-ileus patients had higher frequency of positive anti-Ro and anti-RNP antibodies compared to lupus patients without pseudo-ileus, was reported by Mok et al. [10].

Moreover, based on literatures, ascites occurs in $8-11 \%$ of adult patients with SLE [11]. The course

Table 1 Laboratory findings of ascites

\begin{tabular}{ll}
\hline Variables & Results \\
\hline Appearance & Yellow \\
Transparency & Transparent \\
Rivalta test & Postive \\
Protein (g/L) & 30.2 \\
Albumin ( $/ \mathrm{L}$ ) & 12.3 \\
Amylase (IU/L) & $<30$ \\
Glucose (mmol/L) & 5.37 \\
LDH (U/L) & 978 \\
Effusion-serum protein proportion & 0.92 \\
Effusion-serum LDH proportion & 7.13 \\
Serum-ascites albumin gradient & 6.2 \\
(SAAG) (g/L) & \\
Nucleated cell count (per uL) & 401 \\
Cytology & Neutrophils (60.4\%), lymphocytes \\
& and mesothelial cells, but no tumor \\
Tuberculosis smear & cells \\
Bacterial and tuberculosis culture & Negative \\
\hline
\end{tabular}


Table 2 Laboratory tests of blood count, liver and renal function and tumour markers

\begin{tabular}{lll}
\hline Variables & Values & References \\
\hline WBC $\left(10^{9} / \mathrm{L}\right)$ & 16.84 & $3.5-9.5$ \\
$\mathrm{Hb}(\mathrm{g} / \mathrm{dL})$ & 10.1 & $11.5-15.5$ \\
Platelet $\left(10^{9} / \mathrm{L}\right)$ & 202 & $125-350$ \\
C-reactive protein $(\mathrm{mg} / \mathrm{L})$ & 10.7 & $0.0-8.0$ \\
ESR $(\mathrm{mm} / \mathrm{h})$ & 6 & $<26$ \\
Cr $(\mathrm{umol} / \mathrm{L})$ & 44.1 & $44.0-133.0$ \\
BUN $(\mathrm{mmol} / \mathrm{L})$ & 5.28 & $2.9-8.2$ \\
Total protein $(\mathrm{g} / \mathrm{L})$ & 32.7 & $65.0-85.0$ \\
Albumin $(\mathrm{g} / \mathrm{L})$ & 18.5 & $40.0-55.0$ \\
Urinalysis: protein/blood & $+/-$ & - \\
Urine protein $(\mathrm{mg} / \mathrm{L})$ & 408 & $0-100$ \\
24 h urine protein $(\mathrm{mg})$ & 1428 & $24-141$ \\
AFP $(\mathrm{ng} / \mathrm{mL})$ & 1.88 & $<20.00$ \\
CEA (ng/mL) & 0.54 & $<4.70$ \\
CA-125 (U/mL) & 38.4 & $<35.0$ \\
CA-199 (U/mL) & 7.35 & $<16.30$ \\
NSE (ng/mL) & 10.56 & $<16.30$ \\
\hline
\end{tabular}

of differentiating a patient with an acute abdomen secondary to SLE as the sole presenting symptom is a real challenge. For our case, the dilatation of jejunum, presence of massive ascites, elevated white blood cell count and failed conservative regimen to alleviate the severe abdominal pain prompted us to perform a laparoscopy to exclude any surgical emergency. Common CT findings in patients with LMV include dilated bowel, focal or diffuse bowel-wall thickening, abnormal bowel-wall enhancement (a double halo or target sign), mesenteric oedema, engorgement of mesenteric vessels (comb sign) and ascites [12-15]. These signs are also shared by disorders such as mechanical bowel obstruction and inflammatory bowel disease, which can limit the accuracy of the diagnosis. Nevertheless, CT findings can help to differentiate LMV from thrombo embolic disease [16]. Literatures have reported that surgical intervention improves prognosis of patients who fail to respond to conservative management [6].

In addition, Fitz-Hugh-Curtis syndrome was initially suspected. In 1930, Curtis [17] reported the violin-string appearance between the anterior hepatic surface and abdominal wall. This was also observed in our patient. However, the patient revealed that she had her first sexual intercourse 2 months ago, using condom as barrier method. The bacterial culture was negative and there was no sign of tuberculosis. Laparoscopy has been postulated as the gold standard for diagnosing Fitz-Hugh-Curtis syndrome [18].
Table 3 Laboratory tests of autoimmune diseases

\begin{tabular}{|c|c|c|}
\hline Variables & Results & References \\
\hline Anti-nuclear antibody, titer & Positive, 1:3200 & - \\
\hline A- $\beta 2-G P 1 \quad(R U / m L)$ & 3.4 & $<20.0$ \\
\hline A-dsDNA-3 (IU/mL) & 80.1 & $<100$ \\
\hline Anti-cardiolipin lgG (U) & 5.7 & $<20.0$ \\
\hline Anti-U1-snRNP & Positive & - \\
\hline Anti-SmD1 & Positive & - \\
\hline Anti-RPP & - & - \\
\hline Anti-nucleosome & - & - \\
\hline Anti-histone & - & - \\
\hline Anti-SSA/Ro52 & Positive & - \\
\hline Anti-SSA/Ro60 & Positive & - \\
\hline Anti-SSB-2e & - & - \\
\hline Anti-Scl-70 & - & - \\
\hline Anti-CenpB & - & - \\
\hline Anti-Jo-1 & - & - \\
\hline Anti-Mi-2 & - & - \\
\hline Anti-PM-Scl & - & - \\
\hline Anti-Ku & - & - \\
\hline Anti-PCNA & - & - \\
\hline AMA-M2-2 & - & - \\
\hline Anti-dsDNA & Weakly positive & - \\
\hline $\lg G(g / L)$ & 14.5 & $7.00-16.00$ \\
\hline $\lg A(g / L)$ & 1.7 & $0.70-4.00$ \\
\hline $\lg M(g / L)$ & 1.12 & $0.400-2.300$ \\
\hline C3 (g/L) & 0.2 & $0.9-1.8$ \\
\hline $\mathrm{C} 4(\mathrm{~g} / \mathrm{L})$ & $<0.064$ & $0.100-0.400$ \\
\hline
\end{tabular}

We, therefore, conclude that diagnosing a patient with acute abdomen secondary to SLE remains a clinical challenge. Surgical intervention helps to alleviate the acute abdomen and exclude any surgical emergency when conservative approach fails. Nevertheless, this is a single case study and conclusion may only be drawn from our experience.

\section{Abbreviations}

$\mathrm{CT}$ : Computer tomographyANAAnti-nuclear antibody; LMV: Lupus mesenteric vasculitis; POD: Post-operative day; SLE: Systematic lupus erythematosus;

SLEDAl: Systematic lupus erythematosus disease activity index

\section{Acknowledgments}

We will like to thank Dr. Zhongyang Ding from the Radiology Department of The First Affiliated Hospital of Nanjing Medical University for the radiological images.

\section{Authors' contributions}

KS, DR and XP all have made substantial contributions to conception, acquisition of data, analysis, and interpretation of data. All of them have been involved in drafting the manuscript and revising it critically for important intellectual content. All authors read and approved the final 
manuscript and take public responsibility for appropriate portions of the content and agreed to be accountable for all aspects of work.

\title{
Funding
}

These case reports did not receive any specific grant from funding agencies. in the public, commercial, or not-for-profit sectors.

\section{Availability of data and materials}

\author{
Not applicaple
}

\section{Ethics approval and consent to participate}

Not applicable.

\section{Consent for publication}

Written informed consent was obtained from the participants for publication of this article and any accompanying tables/images. A copy of the written. consent is available for review by the Editor of this journal.

\section{Competing interests}

The authors declare that they have no competing interests.

Received: 4 October 2018 Accepted: 19 June 2019

Published online: 02 July 2019

\section{References}

1. Alves SC, Fasano S, Isenberg DA. Autoimmune gastrointestinal complications in patients with systemic lupus erythematosus: case series and literature review. Lupus. 2016;25(14).

2. Hiraishi $\mathrm{H}$, et al. Massive gastrointestinal hemorrhage in systemic lupus erythematosus: successful treatment with corticosteroid pulse therapy. Am J Gastroenterol. 1999;94(11):3349.

3. Laing TJ. Gastrointestinal vasculitis and pneumatosis intestinalis due to systemic lupus erythematosus: successful treatment with pulse intravenous cyclophosphamide. Am J Med. 1988;85(4):555-8.

4. Lee MG, Hagley K, Decuaelar K. Intestinal ischemia in systemic lupus erythematosus. J Natl Med Assoc. 2008;100(6):721-3.

5. Alhakeem MS, Mcmillen MA. Evaluation of abdominal pain in systemic lupus erythematosus. Am J Surg. 1998;176(3):291-4.

6. Medina F, et al. Acute abdomen in systemic lupus erythematosus : The Importance of Early Laparotomy. Am J Med. 1997;103(2):100.

7. Bombardier, C., et al., Derivation of the sledai. A disease activity index for lupus patients. 1992. 630\&ndash;640.

8. Kishimoto $\mathrm{M}$, et al. Acute gastrointestinal distress syndrome in patients with systemic lupus erythematosus. Lupus. 2007;16(2):137-41.

9. Nojima $Y$, et al. Chronic intestinal pseudoobstruction associated with autoantibodies against proliferating cell nuclear antigen. Arthritis \& Rheumatology. 2010;39(5):877-9.

10. Mok MY, Wong RW, Lau CS. Intestinal pseudo-obstruction in systemic lupus erythematosus: an uncommon but important clinical manifestation. Lupus. 1998;9(1):11.

11. Weinstein PJ, Noyer CM. Rapid onset of massive ascites as the initial presentation of systemic lupus erythematosus. Am J Gastroenterol. 2000;95(1):302-3.

12. Ha HK, et al. Radiologic features of vasculitis involving the gastrointestinal tract. Radiographics. 2000;20(3):779-94.

13. Byun JY, et al. CT features of systemic lupus erythematosus in patients with acute abdominal pain: emphasis on ischemic bowel disease. Radiology. 1999;211(1):203-9.

14. Ko SF, et al. CT findings at lupus mesenteric vasculitis. Acta Radiol. 1997;38(1):115-20.

15. Tian XP, Zhang X. Gastrointestinal involvement in systemic lupus erythematosus: insight into pathogenesis, diagnosis and treatment. World J Gastroenterol. 2010;16(24):2971-7.

16. Kaushik $\mathrm{S}$, et al. Abdominal thrombotic and ischemic manifestations of the antiphospholipid antibody syndrome: CT findings in 42 Patients1. Radiology. 2001;218(3):768-71.

17. Curtis A. A case of adhesion in the right upper quadrant. Jama. 1930;94.

18. You JS, et al. Clinical features of Fitz-Hugh-Curtis syndrome in the emergency department. Yonsei Med J. 2012;53(4):753-8.

\section{Publisher's Note}

Springer Nature remains neutral with regard to jurisdictional claims in published maps and institutional affiliations.

Ready to submit your research? Choose BMC and benefit from:

- fast, convenient online submission

- thorough peer review by experienced researchers in your field

- rapid publication on acceptance

- support for research data, including large and complex data types

- gold Open Access which fosters wider collaboration and increased citations

- maximum visibility for your research: over $100 \mathrm{M}$ website views per year

At $\mathrm{BMC}$, research is always in progress.

Learn more biomedcentral.com/submissions 